\title{
Efficacy and safety of intravenous iron sucrose in treating adults with iron deficiency anemia
}

Rodolfo Delfini Cançado

Pedro Otavio Novis de Figueiredo

Maria Cristina Albe Olivato

Carlos Sérgio Chiattone

Hematology-Oncology Department, Faculdade de Ciências Médicas da Santa Casa de São Paulo - FCMSCSP São Paulo, SP, Brazil
Conflict-of-interest disclosure:

The authors declare no competing

financial interest

Submitted: 9/24/2011

Accepted: 10/24/2011

Corresponding author:

Rodolfo Delfini Cançado

Hemocentro da Santa Casa de São Paulo

Rua Marquês de Itú, 579 - $3^{\circ}$ andar

01223-001 - São Paulo, SP, Brazil

Phone : $55112176-7255$

rdcan@uol.com.br

www.rbhh.org or www.scielo.br/rbhh

DOI: 10.5581/1516-8484.20110119
Background: Iron deficiency is the most common disorder in the world, affecting approximately $25 \%$ of the world's population and the most common cause of anemia.

Objective: To evaluate the efficacy and safety of intravenous iron sucrose (IS) in the treatment of adults with iron deficiency anemia

Methods: Eighty-six adult patients with iron deficiency anemia, who had intolerance or showed no effect with oral iron therapy, received a weekly dose of $200 \mathrm{mg}$ of intravenous iron sucrose until the hemoglobin level was corrected or until receiving the total dose of intravenous iron calculated for each patient

Results: The mean hemoglobin and serum ferritin levels were $8.54 \mathrm{~g} / \mathrm{dL}$ and $7.63 \mathrm{ng} / \mathrm{mL}$ (pretreatment) and $12.1 \mathrm{~g} / \mathrm{dL}$ and $99.0 \mathrm{ng} / \mathrm{mL}$ (post-treatment) (p-value $<0.0001)$, respectively. The average increases in hemoglobin levels were $3.29 \mathrm{~g} / \mathrm{dL}$ for women and $4.58 \mathrm{~g} / \mathrm{dL}$ for men; $94 \%$ of male and $84 \%$ of female patients responded (hemoglobin increased by at least $2 \mathrm{~g} / \mathrm{dL}$ ) to intravenous iron therapy. Correction of anemia was obtained in 47 of 69 (68.1\%) female patients and in 12 of 17 male (70.6\%) patients. A total of 515 intravenous infusions of iron sucrose were administered and iron sucrose was generally well tolerated with no moderate or serious adverse drug reactions recorded by the investigators.

Conclusions: Our data confirm that the use of intravenous iron sucrose is a safe and effective option in the treatment of adult patients with iron deficiency anemia who lack satisfactory response to oral iron therapy. Intravenous iron sucrose is well tolerated and with a clinically manageable safety profile when using appropriate dosing and monitoring. The availability of intravenous iron sucrose would potentially improve compliance and thereby reduce morbidities from iron deficiency.

Keywords: Iron deficiency; Anemia, iron-deficiency; Iron compounds; Infusions, intravenous

\section{Introduction}

Iron deficiency is the most common disorder in the world, affecting approximately $25 \%$ of the world's population, and the most common cause of anemia. ${ }^{(1,2)}$ The first choice in the treatment of iron deficiency anemia (IDA) for almost all patients is oral iron replacement because of its effectiveness, safety and low cost. Its efficacy may, however, be limited in many patients because of the side effects related to the drug, particularly gastrointestinal toxicity occurring in $35 \%$ to $59 \%$ of patients and the long course needed to treat anemia and replenish iron stores. ${ }^{(3,4)}$ Non-adherence to a prescribed course of oral iron is common and, even in adherent patients, poor intestinal absorption fails to compensate for iron need in the presence of ongoing blood losses. ${ }^{(3,4)}$

While intravenous (IV) iron has the capability of bypassing all these issues, concerns remain about the acute safety profiles of the available products and the potential for longterm harm from repeated iron administration. ${ }^{(5,6)}$

Parenteral iron preparations available in the past were associated with a high incidence of life-threatening anaphylactic reactions and death, which made physicians reluctant to use them. The formulation most frequently responsible for these serious adverse events, observed in 0.6 to $2.3 \%$ of the patients, was the high-molecular-weight iron dextran. ${ }^{(7,8)}$ However, the availability of new preparations (iron sucrose, ferric gluconate, low-molecularweight iron dextran, and, more recently, ferric carboxymaltose, iron isomaltoside and ferumoxytol) with much better safety profiles, is changing the pattern of the use of IV iron in a number of clinical settings. ${ }^{(5,9-20)}$

The objectives of this phase IV study were to evaluate the efficacy of IV iron sucrose to treat adult IDA patients and to determine the safety and tolerability of this drug. 


\section{Methods}

\section{Study design}

This open-label, retrospective, cross-sectional phase IV trial with IV iron sucrose treatment in patients with IDA was carried out in one center in Brazil. The trial was conducted in accordance with Good Clinical Practice, as outlined in the International Conference on Harmonization guidelines. Approval of the Research Ethics Committee of Santa Casa of Sao Paulo was obtained and either written informed consent from patients or an informed consent waiver was obtained.

\section{Patient eligibility}

Eligible patients were aged 18 years or older with IDA. Patients were selected in accordance with the inclusion criteria of IDA: hemoglobin $(\mathrm{Hb})$ level $<12.0 \mathrm{~g} / \mathrm{dL}$ for women and $<13.0 \mathrm{~g} / \mathrm{dL}$ for men, serum ferritin (SF) level $<12 \mathrm{ng} / \mathrm{mL}$ and all patients had been unresponsive or had had poor responses to oral iron therapy $(\mathrm{Hb}$ increases $<2 \mathrm{~g} / \mathrm{dL}$ using 160-200 mg/day of oral ferrous sulphate over 4 weeks of treatment) or had been unable to tolerate oral iron therapy because of gastrointestinal side effects.

Patients with history of hypersensitivity to iron sucrose or any component of the formulation, evidence of iron overload, anemia not caused by iron deficiency, acute or chronic bacterial infection and pregnant women with gestational age less than 16 weeks were excluded from participating in this study.

\section{Treatment plan - Schedule of intravenous infusions}

All eligible patients received a weekly dose of $200 \mathrm{mg}$ of iron sucrose diluted in $250 \mathrm{~mL} 0.9 \%$ sodium chloride solution administered intravenously over 45 minutes. No test dose was given.

The total iron dose (TID) was calculated according to the Ganzoni's formula: TID $(\mathrm{mg})=$ weight $(\mathrm{Kg}) \times$ [(ideal $\mathrm{Hb}-$ actual $\mathrm{Hb}$ ) g/dL] x $0.24+500 \mathrm{mg}$ (depot iron), rounded up to the nearest multiple of $100 \mathrm{mg}$. Ideal $\mathrm{Hb}$ in grams per liter was set at $12.0 \mathrm{~g} / \mathrm{dL}$ for women and $13.0 \mathrm{~g} / \mathrm{dL}$ for men. Additional oral iron was not administered during the study. ${ }^{(6)}$

Treatment was continued until $\mathrm{Hb}$ correction or completing the administration of the total dose calculated of IV iron for each patient. Treatment was stopped earlier in patients who reached a $\mathrm{Hb}$ concentration greater than $14.0 \mathrm{~g} / \mathrm{dL}$ or SF level greater than $300 \mathrm{ng} / \mathrm{mL}$ before the administration of the total IV iron calculated for each patient; due to consent withdrawal or lost to follow up, pregnancy, intercurrent illness or adverse events.

\section{Safety and efficacy assessments}

Iron sucrose infusions were administered in the Hematology Unit in an outpatient setting, and all patients were observed for one hour after the infusions. All adverse events (AE) after IV infusions were identified by physical examination and because of injury to the patient, using standard forms encoded for AE. The blood pressure was measured before, during, and after each infusion. A serious $\mathrm{AE}$ was defined as a medically significant event that was either fatal or life-threatening, required surgical intervention, prolonged hospitalization or resulted in persistent disability. All AE were assessed by the investigator for a possible relationship with the study drug.

Study visits and laboratory assessments were performed at screening and every 2 weeks during treatment period. Laboratory assessments performed included complete blood counts with differential counts, reticulocyte count, electrolytes, glucose, liver function tests, lactate dehydrogenase, C-reactive protein and markers of iron metabolism (SF, serum iron and total ironbinding capacity). Transferrin saturation was calculated from serum iron $(\mathrm{Fe})$ and serum iron-binding capacity according to the formula: $\mathrm{Fe}(\mu \mathrm{g} / \mathrm{dL}) /$ serum iron-binding capacity (mg/dL) x 100 .

The efficacy of IV iron sucrose was evaluated for all participants by determining changes in $\mathrm{Hb}, \mathrm{SF}$ and transferrin saturation levels assessed every 2 weeks. Responders to IV iron therapy were defined as those patients whose $\mathrm{Hb}$ concentration increased by at least $2 \mathrm{~g} / \mathrm{dL}$ from baseline value by the end of study.

Lower and upper Gastrointestinal (GI) tract evaluations were performed to diagnose the cause of IDA particularly in men $\geq 50$ and in post-menopausal women, in whom IDA was suspected to occur due to bleeding.

\section{Statistical analysis}

All patients in the database who fulfilled inclusion and exclusion criteria comprised the analysis population. The data were analyzed under supervision of the trial statistician and were reviewed by the investigators. Descriptive summary statistics for background demographic and clinical characteristics were provided. The assessment of safety was based mainly on the frequency of AEs and on the number of laboratory values that fell outside the predetermined ranges. All safety data are reported for patients who received at least one dose of study medication.

The main efficacy endpoints were changes in $\mathrm{Hb}, \mathrm{SF}$ and transferrin saturation from baseline compared to the end of the study (EOS).

All data were analyzed using the Statistical Package for the Social Sciences (SPSS) version 12.0 computer program. Summary data are presented as means \pm standard deviation. Multiple comparisons were made by paired two- 
sample Student's t test. A two-tailed probability value of 0.05 was considered statistically significant.

\section{Results}

\section{Patients' baseline characteristics}

A total of 100 consecutive adult patients were screened between January 2006 and August 2009 and 86 were enrolled (14 patients did not fulfill the inclusion criteria). All patients enrolled completed the treatment.

Mean age \pm SD and median age were $26.9 \pm 12.5$ years and 42.5 years (range: from 20 to 76 ), respectively; sixty-nine $(80 \%)$ patients were women and 8 of whom $(11.6 \%)$ were pregnant.

Cause of iron deficiency anemia and indications for intravenous iron treatment

The most common cause of IDA was abnormal uterine bleeding observed in $60.0 \%(41 / 69)$ of female patients and Roux-en-Y gastric bypass/bariatric surgery in $53.0 \%(9 / 17)$ of male patients. The most frequent pathological conditions of the gastrointestinal tract associated with IDA were erosive esophagitis/gastritis (12 patients), hiatal hernia (two patients), gastric ulcer/carcinoma (two patients), vascular ectasia (two patients), ulcerative colitis (two patients) and Crohn's disease (two patients). The indications for using IV iron sucrose were intolerance to oral iron (51 patients, 59.3\%) and lack of response to oral iron therapy (35 patients, $40.7 \%$ ).

\section{Efficacy}

\section{Changes in Hb levels}

The mean \pm SD Hb concentration $(\mathrm{g} / \mathrm{dL})$ increased significantly by the EOS compared to baseline (from $8.54 \pm$ 1.39 to $12.1 \pm 1.41 ; \mathrm{p}<0.0001$ - Table 1$)$. The mean increases in $\mathrm{Hb}$ concentration were $3.29 \mathrm{~g} / \mathrm{dL}$ and $4.58 \mathrm{~g} / \mathrm{dL}$ for women and men, respectively.
Responders were defined as patients who had increases in $\mathrm{Hb}$ concentrations of at least $2 \mathrm{~g} / \mathrm{dL}$ from baseline value by the EOS; 16 of 17 male patients (94\%) and 58 of $59(84 \%)$ female patients responded to IV iron therapy. Correction of anemia was obtained in 47 of 69 (68.1\%) female patients and in 12 of 17 (70.6\%) male patients.

None of the 86 study participants required red blood cell transfusions during or after completing the treatment. levels

Changes on transferrin saturation and serum ferritin

Mean transferrin saturation (\%) and SF levels $(\mu \mathrm{g} / \mathrm{L})$ increased significantly by the EOS compared to baseline (from $4.6 \pm 4.0 \%$ to $23.0 \pm 15.4 \%$; $<<0.0001$ and from 7.6 $\pm 6.6 \mu \mathrm{g} / \mathrm{L}$ to $99.0 \pm 79.0 \mu \mathrm{g} / \mathrm{L} ; \mathrm{p}=0.0001$, respectively Table 1).

\section{Patient exposure to treatment}

Mean \pm SD and median IV iron sucrose dosage over the study period were $1200 \mathrm{mg} \pm 300 \mathrm{mg}$ and $1200 \mathrm{mg}$ (range: $600 \mathrm{mg}$ to $2200 \mathrm{mg}$ ), respectively. Median IV iron sucrose treatment duration was 6 weeks (range: from 5 to 11 weeks).

\section{Safety and tolerability}

A total of $515 \mathrm{IV}$ infusions were administered and iron sucrose was generally well tolerated. There were no deaths during the study and no moderate or serious AE were recorded (no episodes of anaphylaxis and no hypotensive attacks). Treatment was not discontinued in any patient due to drug-related AE.

The most frequent drug-related (investigatorassessed) AEs were transient and mild and included: burning at the site of venipuncture (seven patients), bitter taste (five patients), mild and transient hypotension (two patients), nausea (five patients), maculopapular skin rash (one patient) and palpitations (one patient).

\begin{tabular}{|c|c|c|c|}
\hline Patient characteristic & Baseline & End of the study & $\begin{array}{l}\mathrm{p} \text {-value } \\
\text { paired two-sample } t \text { test }\end{array}$ \\
\hline \multicolumn{4}{|l|}{ Hemoglobin (g/dL) } \\
\hline Mean \pm standard deviation & $8.54 \pm 1.39$ & $12.1 \pm 1.41$ & $<0.0001$ \\
\hline Median (range) & $8.8(4.8-10.6)$ & $12.1(8.4-14.8)$ & \\
\hline \multicolumn{4}{|l|}{ Transferrin saturation (\%) } \\
\hline Mean \pm standard deviation & $4.6 \pm 4.0$ & $23.0 \pm 15.4$ & 0.0001 \\
\hline Median (range) & $4.0(1.5-23)$ & $20.0(5.5-41.0)$ & \\
\hline \multicolumn{4}{|l|}{ Serum ferritin $(\mu \mathrm{g} / \mathrm{L})$} \\
\hline Mean \pm standard deviation & $7.6 \pm 6.6$ & $99.0 \pm 79.0$ & $<0.0001$ \\
\hline Median (range) & $5.0(1.0-10.0)$ & $68.8(5.3-383.0)$ & \\
\hline
\end{tabular}




\section{Discussion}

The first choice treatment of IDA is oral iron replacement because of its effectiveness, safety and low cost. Oral iron supplementation is adequate in most clinical conditions and in the absence of inflammation or significant ongoing blood loss, can correct the anemia. ${ }^{(5,6,11)}$

However, many clinical studies have demonstrated the high incidence of side effects related to this type of therapy, particularly with ferrous sulphate compounds, causing lack of compliance and suboptimal results. ${ }^{(3,4)}$

Intravenous iron therapy has been indicated in situations such as intolerance of or contraindications to oral iron, in cases of severe anemia especially if accompanied by significant ongoing bleeding (when iron loss exceeds that that can be met by oral therapy), inflammatory diseases and in patients with IDA scheduled for elective surgery. ${ }^{(11,14)}$

Similar to previous investigations, the most common causes of IDA in the current study were abnormal uterine bleeding in women and gastrointestinal surgery in men and the main indication for IV iron was intolerance to oral iron because of gastrointestinal side effects. ${ }^{(16)}$

Menorrhagia is a significant cause of ill health affecting approximately $30 \%$ of women and the main symptom for gynecologic surgeries, including hysterectomy. It is clinically defined as a blood loss of $\geq 80 \mathrm{~mL}$ per menstrual cycle and can adversely affect the physical and mental health and thus has a detrimental impact on the quality of life. $^{(21)}$

Iron bioavailability is compromised after gastric and bariatric surgeries owing to a combination of decreased food intake, lack of gastric acidity and bypass of the duodenum, where most iron is absorbed. Increased iron loss can also occur from blood loss from the blind intestinal loops or ulcers at the anastomotic sites. ${ }^{(22-24)}$

Many clinical studies have demonstrated that IV iron sucrose is a safe and effective alternative to oral iron in the treatment of IDA. ${ }^{(15-18)}$

In this study, it was demonstrated that IV iron sucrose administration is well tolerated with a safety profile and effective in increasing $\mathrm{Hb}$ levels and restoring body iron in adult patients with IDA. The average increases of $\mathrm{Hb}$ were $3.29 \mathrm{~g} / \mathrm{dL}$ in women and $4.58 \mathrm{~g} / \mathrm{dL}$ in men; more than $80 \%$ of women and $90 \%$ of men responded to IV iron therapy and correction of anemia was obtained in about $70 \%$ of the patients.

Iron sucrose complex is effective because of the rapid removal from the plasma and the availability of iron for erythropoiesis. After a bolus dose of iron sucrose, the plasma peak occurs in 10 minutes. Twenty-four hours after administration, the plasma level is negligible, indicating rapid bone marrow uptake as has been shown by positron emission tomography studies. Studies have shown that $70-97 \%$ of the iron is used for erythropoiesis, with only a 4-6\% elimination rate. ${ }^{(25)}$
Iron sucrose is well tolerate with no serious adverse effects and with a lower incidence of adverse allergic reactions. ${ }^{(7-10)}$ Because of this biologic advantage associated to its effective in correcting anemia more rapidly and effectively than oral iron and its safety profile, IV iron sucrose has been approved in the treatment of IDA in many clinical settings such as: during pregnancy ${ }^{(15,17,18)}$ postpartum ${ }^{(19)}$ in inflammatory bowel disease, ${ }^{(14,20,21,24)}$ malignances ${ }^{(26)}$ and during chronic hemodialysis receiving erythropoietin stimulating agents. ${ }^{(12)}$

IV iron sucrose has been reported to be safe with an excellent profile in clinical use; it can be administered without a test dose. The incidence of serious life-threatening anaphylaxis with iron sucrose is $0.002 \%$ versus $0.6-2.3 \%$ and $0.04 \%$ with high-molecular-weight iron dextran and ferric gluconate, respectively. Moreover, fatal hypersensitivity reactions and death have not been reported with iron sucrose..$^{(7-10)}$

In this study, IV iron sucrose was generally well tolerated and treatment was not discontinued in any patient. A total of $515 \mathrm{IV}$ infusions of iron sucrose were administered and, similar to other studies, there were no moderate or serious $\mathrm{AE}$ recorded. ${ }^{(7-10,17-19)}$

\section{Conclusions}

Our data confirm that the use of IV iron sucrose is a safe and effective option in the treatment of adult patients with IDA who do not tolerate or lack satisfactory response to oral iron therapy. IV iron sucrose is well tolerated and has a clinically manageable safety profile when using appropriate dosing and monitoring. The availability of IV iron sucrose would potentially facilitate improved compliance, and thereby reduce morbidity from iron deficiency.

\section{References}

1. World Health Organization. Iron deficiency anemia. Assessment, prevention and control. A guide for programme managers [Internet]. Geneva: WHO; 2001. [cited 2010 Jan 12]. Available from:http:// www.who.int/nutrition/publications/en/ida_assessment_prevention control.pdf.

2. World Health Organization. The World Health Report 2002: Reducing risks, promoting healthy life. Geneva: World Health Organization: 2002.p.1-248.

3. Alleyne M, Horne MK, Miller JL. Individualized treatment for irondeficiency anemia in adults. Am J Med. 2008;121(11):943-8

4. Cançado RD, Lobo C, Friedrich JR. Tratamento da anemia ferropriva com ferro via oral. Rev Bras Hematol Hemoter. 2010;32 (Supl. 2):114-20.

5. Auerbach $\mathrm{M}$, Ballard $\mathrm{H}$. Clinical use of intravenous iron: administration, efficacy and safety. Hematology Am Soc Hematol Educ Program. 2010:338-47.

6. Cançado RD, Lobo C, Friedrich JR. Tratamento da anemia ferropriva com ferro via parenteral. Rev Bras Hematol Hemoter. 2010;32 (Supl. 2):121-8.

7. Fishbane S, Kowalski EA. The comparative safety of intravenous iron dextran, iron saccharate, and sodium ferric gluconate. Semin Dial. 2000;13(6):381-4. 
8. Chertow GM, Mason PD, Vaage-Nilsen O, Ahlmen J. Update on adverse drug events associated with parenteral iron. Nephrol Dial Transplant. 2006;21(2):378-82

9. Auerbach M, Ballard H, Glaspy J. Clinical update: intravenous iron for anaemia. Lancet. 2007;369(9572)1502-4. Comment in: Lancet. 2007;370(9586):481-2; author reply 482-3. Lancet. 2007;370(9586):482; author reply 482-3.

10. Danielson BG. Structure, chemistry, and pharmacokinetics of intravenous iron agents. J Am Soc Nephrol 2004;15:(Suppl 2): S93-8.

11. Muñoz M, Breymann C, García-Erce JA, Gómez-Ramírez S, Comin $\mathrm{J}$, Bisbe E. Efficacy and safety of intravenous iron therapy as an alternative/adjunct to allogeneic blood transfusion. Vox Sang. 2008; 94(3):172-83.

12. Coyne DW, Auerbach M. Anemia management in chronic kidney disease: intravenous iron steps forward. Am J Hematol. 2010; 85(5):311-2. Comment on: Am J Hematol. 2010;85(5):315-9.

13. Gasche C, Berstad A, Befrits R, Beglinger C, Dignass A, Erichsen K, et al. Guidelines on the diagnosis and management of iron deficiency and anemia in inflammatory bowel diseases. Inflamm Bowel Dis. 2007;13(12):1545-53

14. Lindgren S, Wikman O, Befrits R, Blom H, Eriksson A, Granno C, et al. Intravenous iron sucrose is superior to oral iron sulphate for correcting anaemia and restoring iron stores in IBD patients: A randomized, controlled, evaluator-blind, multicentre study. Scand J Gastroenterol. 2009;44(7):838-45.

15. Al RA, Unlubilgin E, Kandemir O, Yalvac S, Cakir L, Haberal A. Intravenous versus oral iron for treatment of anemia in pregnancy. Obstet Gynecol. 2005;106(6):1135-40.

16. Beris P, Maniatis A, on behalf of the NATA Working Group on Intravenous Iron Therapy. Guidelines on intravenous iron supplementation in surgery and obstetrics/gynecology. Transfus Altern Transfus Med. 2007;9(Suppl 1):29.

17. al-Momen AK, al-Meshari A, al-Nuaim L, Saddique A, Abotalib Z, Khashogji $\mathrm{T}$, et al. Intravenous iron sucrose complex in the treatment of iron deficiency anemia during pregnancy. Eur J Obstet Gynecol Reprod Biol. 1996;69(2):121-4.

18. Bhandal N, Russell R. Intravenous versus oral iron therapy for postpartum anaemia. BJOG. 2006;113(11)1248-52. Comment in: BJOG. 2007;114(5):655; author reply 655-6.

19. Van Wyck DB, Martens MG, Seid MH, Baker JB, Mangione A. Intravenous ferric carboxymaltose compared with oral iron in the treatment of postpartum anemia. A randomised controlled trial. Obstet Gynecol. 2007;110(2 Pt 1):267-78.

20. Kulnigg S, Stoinov S, Simanenkov V, Dudar LV, Karnafel W, Garcia $\mathrm{LC}$, et al. A novel intravenous iron formulation for treatment of anemia in inflammatory bowel disease: the ferric carboxymaltose (FERINJECT) randomized controlled trial. Am J Gastroenterol. 2008; 103(5):1182-92

21. Cançado RD, Chiattone CS. Anemia ferropênica no adulto - causas, diagnóstico e tratamento. Rev Bras Hematol Hemoter. 2010;32(3): 240-6.

22. Varma S, Baz W, Badline E, Nakhl F, McMullen H, Nicastro J, et al. Need for parenteral iron therapy after bariatric surgery. Surg Obes Relat Dis. 2008;4(6):715-9.

23. Kim YH, Chung HH, Kang SB, Kim SC, Kim YT. Safety and usefulness of intravenous iron sucrose in the management of preoperative anemia in patients with menorrhagia: a phase IV, open-label, prospective, randomized study. Acta Haematol. 2009; 121(1):37-41

24. Muñoz M, Gómez-Ramírez S, García-Erce JA. Intravenous Iron in inflammatory bowel disease. World J Gastroenterol. 2009;15 (37):4666-74.

25. Lyseng-Williamson KA, Keating GM. Ferric carboxymaltose: a review of its use in iron-deficiency anaemia. Drugs. 2009;69(6): 739-56.

26. Littlewood TJ, Alikhan R. The use of intravenous iron in patients with cancer-related anaemia. Br J Haematol. 2008;141(6):7516. Comment in: Br J Haematol. 2008;143(5):754; author reply 755 . 